\title{
Fuzzy Decision Tree Based Classification of Psychometric Data
}

\author{
Vitaly Levashenko*, Elena Zaitseva*, Krzysztof Pancerz ${ }^{\dagger}$ and Jerzy Gomuła $^{\S}$ \\ ${ }^{*}$ University of Zilina, Slovakia \\ Email: Vitaly.Levashenko@fri.uniza.sk, elena.zaitseva@fri.uniza.sk \\ †University of Management and Administration in Zamość, Poland \\ Email: kpancerz@wszia.edu.pl \\ $\ddagger$ University of Information Technology and Management in Rzeszów, Poland \\ $\S$ The Andropause Institute, Medan Foundation, Warsaw, Poland \\ Email: jerzy.gomula@wp.pl \\ ๑Cardinal Stefan Wyszyński University in Warsaw, Poland
}

\begin{abstract}
For five years, the Copernicus system - a tool for computer-aided diagnosis of mental disorders based on data coming from psychometric tests - has been developed. This tool uses a variety of classification ways for differential interprofile diagnosis. In the current version of the tool, psychometric data come from the Minnesota Multiphasic Personality Inventory (MMPI) test. In this paper, we describe another machine learning approach, based on fuzzy decision trees, for classification of psychometric data. The algorithm for generation of fuzzy decision trees used by us is based on cumulative information estimations of initial data. Due to the promising results of classification of MMPI data, the presented approach will be implemented in the Copernicus system.
\end{abstract}

\section{INTRODUCTION}

$\mathbf{S}$ O FAR, there have not been developed universal machine learning and data mining methods which could be applied for each kind of data, delivering expected results. Each kind of data requires an individual approach to them, and what follows, designing suitable, specialized methods for them. Classification models can be obtained in various ways (cf. [1], [2], [3]). Each way leads to obtaining a set of rules characterized by different coefficients describing their classification ability/quality. One of the main tasks of building decision support systems for computer-aided diagnosis of patients is to search for efficient methods of classification of new cases unseen earlier. Our research concerns psychometric data coming from the Minnesota Multiphasic Personality Inventory (MMPI) test [4]. MMPI is used to count the personalitypsychometric dimensions which help in diagnosis of mental diseases. A brief information about this test is included in Section II.

In years 1998-1999, a team of researchers consisting of W. Duch, T. Kucharski, J. Gomuła, R. Adamczak created two independent rule systems devised for the nosological diagnosis of persons that may be screened with the MMPI-WISKAD test [5]. In the literature, we can also find descriptions of some other computer tools for classification of MMPI profiles, e.g., based on the Fortran program [6], "Panda" [7]. However, these tools are now mature. For five years, our research has been focused on creating a new computer tool called the Copernicus system. We started creation of the system in 2009. The main goal of this tool is to support clinical psychologists in differential and clinical diagnosis based on the overall analysis of profiles of patients examined by means of personality inventories. The tool has been designed for the Java platform. We can distinguish three main parts of the Copernicus system:

- Knowledge base.

- Multiway classification engine.

- Visualization engine.

The development of the Copernicus system (consecutive versions) over five years has been described in [8], [9], [10].

In the paper, we describe another machine learning approach that we plan to implement in the Copernicus system. This approach uses fuzzy decision trees proposed in [11]. That approach, based on cumulative information estimations of initial data, is brought back in Section III. Results of experiments made on over 1700 cases showed that the approach looks very promising.

\section{MMPI DATA}

The Minnesota Multiphasic Personality Inventory (MMPI) test [4] delivers psychometric data on patients with selected mental disorders. Originally, the MMPI test was developed and published in 1943 by a psychologist S.R. McKinley and a neuropsychiatrist J.Ch. Hathaway from the University of Minnesota. Later, the inventory was adapted in above fifty countries. The MMPI-WISKAD personality inventory is the Polish adaptation of the American inventory. It has been used, among other modern tools, for carrying out nosological differential diagnosis in psychiatric wards. MMPI is also commonly used in scientific research. The test is based upon the empirical approach and originally was translated by $\mathrm{M}$. Chojnowski (as WIO) [12] and elaborated by Z. Płużek (as WISKAD) in 1950 [13]. American norms were accepted there. Based upon received responses ("Yes", "Cannot Say", "No") to selected questions we may make up a diagnosis for the subject being examined. 
After examination by means of the MMPI test, each case (patient) $x$ is described by a data vector $A(x)$ consisting of thirteen descriptive attributes: $A(x)=$ $\left[A_{1}(x), A_{2}(x), \ldots, A_{13}(x)\right]$. A data vector is the so-called MMPI profile. The profile always has a fixed and invariable order of its constituents (attributes). If we have training data, then to each case $x$ we also add one decision attribute $C l$ - a class (nosological type or reference class) to which a patient is classified. For the training data (which are used to learn or extract relationships between data), we have a tabular form (see example in Table I) which is formally called a decision system (decision table) $S=(O b j, A t t r, C l)$ in the Pawlak's form [14]. $O b j$ is a set of cases (patients), Attr is a set of descriptive attributes corresponding to scales, and $\mathrm{Cl}$ is a decision attribute determining a decision class.

The MMPI profile (data vector) can be divided into two parts. The validity part of the profile consists of three scales: $L$ (laying) - attribute $A_{1}, F$ (atypical and deviational answers) - attribute $A_{2}, K$ (self-defensive mechanisms) - attribute $A_{3}$. The clinical part of the profile consists of ten scales: $1 . H p$ (Hypochondriasis) - attribute $A_{4}, 2 . D$ (Depression)- attribute $A_{5}, 3 . H y$ (Hysteria) - attribute $A_{6}$, 4.Ps (Psychopathic Deviate) - attribute $A_{7}, 5 . M f$ (Masculinity/Femininity) - attribute $A_{8}$, 6.Pa (Paranoia) - attribute $A_{9}$, 7.Pt (Psychasthenia) attribute $A_{10}, 8 . S c$ (Schizophrenia) - attribute $A_{11}, 9 . M a$ (Hypomania) - attribute $A_{12}, 0 . I t$ (Social introversion) - attribute $A_{13}$. The clinical scales have numbers attributed to them so that a profile can be encoded to avoid negative connotations connected with the names of scales. Values of attributes are expressed by the so-called T-scores. The T-scores scale, which is traditionally attributed to MMPI, represents the following parameters: offset ranging from 0 to $100 \mathrm{~T}$-scores, average equal to $50 \mathrm{~T}$-scores, standard deviation equal to $10 \mathrm{~T}$-scores.

In our experiments, we have used a data set, collected by $\mathrm{T}$. Kucharski and J. Gomuła from the Psychological Outpatient Clinic, consisting of over 1700 patients (women) classified by a clinic psychologist. The data for the analysis (i.e., profiles of patients) were selected using the competent judge method (the majority of two-thirds of votes of three experts). Each case is assigned to one of nineteen nosological classes and the reference class (norm). Each class corresponds to one of psychiatric nosological types: neurosis (neur), psychopathy (psych), organic (org), schizophrenia (schiz), delusion syndrome (del.s), reactive psychosis (re.psy), paranoia (paran), sub-manic state (man.st), criminality (crim), alcoholism (alcoh), drug addiction (drug), simulation (simu), dissimulation (dissimu), and six deviational answering styles (dev1, dev2, $\operatorname{dev} 3, \operatorname{dev} 4, \operatorname{dev} 5, \operatorname{dev} 6)$.

\section{FuZZY Decision TREeS}

A new greedy version of the Fuzzy ID3 algorithm based on cumulative information estimations of initial data has been proposed in [11]. It can be used to generate understandable fuzzy classification rules. Cumulative information estimations have been introduced in [15]. In this section we briefly recall basics of the Fuzzy ID3 algorithm.
Let us assume, that data describing cases are collected in the form of a decision system (decision table) $S=(\mathrm{Obj}, \mathrm{Attr}, \mathrm{Cl})$ (cf. Section II). In the recalled approach, for each real valued attribute $A_{i} \in$ Attr describing cases, fuzzy partitions $A_{i_{1}}$, $A_{i_{2}}, \ldots, A_{i_{k_{i}}}$, with ranges $[0,1]$, are determined (see an example in Figure 1). The fuzzification of attribute values $A_{i}(u)$ for a given case $u \in O b j$ is performed by analysing the corresponding values of membership functions, i.e., $\mu_{A_{i 1}}(u)$, $\mu_{A_{i 2}}(u), \ldots, \mu_{A_{i k}}(u)$. Analogously, the decision attribute $C l$ can be fuzzified, i.e., we obtain $C l_{1}, C l_{2}, \ldots, C l_{m}$. In case of symbolic decision attribute values, a number of partitions is equal to the number of possible values of this attribute and membership functions take values either 0 or 1 . Each attribute value can be seen as a likelihood estimate. In the approach, a particular case is assumed when the sum of membership function values of all partitions equals to 1 . To transform numeric attribute values to triangular fuzzy data, the algorithm presented in [16] is used.

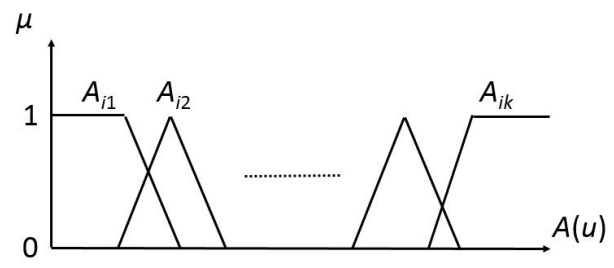

Fig. 1. An example of fuzzy partitions.

The cardinality measure $M\left(A_{i_{1}}\right)$ for each $A_{i_{1}}$ is calculated as:

$$
M\left(A_{i_{1}}\right)=\sum_{u \in O b j} \mu_{A_{i 1}}(u)
$$

The cumulative joint information $J I$ for $C l_{j}$ is:

$$
J I\left(C l_{j}\right)=\log _{2} N-\log _{2} M\left(C l_{j}\right),
$$

where $N$ is a number of cases, i.e., the cardinality of $O b j$.

The cumulative joint information $J I$ for $C l_{j}$ and $\mathbf{A}_{q}$ is:

$J I\left(C l_{j}, \mathbf{A}_{q}\right)=\log _{2} N-\log _{2} M\left(C l_{j} \times A_{i_{1}} \times \cdots \times A_{q_{k_{q}}}\right)$

The cumulative conditional entropy $\mathrm{H}$ between $\mathrm{Cl}$ and $A_{i_{q}}$ with a given $\mathbf{A}_{q}$ is:

$H\left(B \mid \mathbf{A}_{q}, A_{i_{q}}\right)=\sum_{j=1}^{m} M\left(B_{j} \times \mathbf{A}_{q}\right) \times\left[J I\left(B_{j}, \mathbf{A}_{q}\right)-J I\left(\mathbf{A}_{q}\right)\right]$

The cumulative conditional entropy $H$ between $C l$ and $A_{i}$ with a given $\mathbf{A}_{q}$ is:

$$
H\left(B \mid \mathbf{A}_{q}, A_{i}\right)=\sum_{j=1}^{k_{i}} H\left(B \mid \mathbf{A}_{q}, A_{i_{k_{i}}}\right) .
$$

The cumulative mutual information $I$ for $A_{i}$ with a given $\mathbf{A}_{q}$ is:

$$
I\left(B \mid \mathbf{A}_{q}, A_{i}\right)=H\left(B \mid \mathbf{A}_{q}\right)-H\left(B \mid \mathbf{A}_{q}, A_{i}\right) .
$$

These information estimations are used for forming new criteria of fuzzy decision tree induction (see [11]). 
TABLE I

THE TRAINING DATA (FRAGMENT)

\begin{tabular}{|c||c|c|c|c|c|c|c|c|c|c|c|c|c||c|}
\hline Attribute & $A_{1}$ & $A_{2}$ & $A_{3}$ & $A_{4}$ & $A_{5}$ & $A_{6}$ & $A_{7}$ & $A_{8}$ & $A_{9}$ & $A_{10}$ & $A_{11}$ & $A_{12}$ & $A_{13}$ & $C l$ \\
\hline \hline Scale & $L$ & $F$ & $K$ & $1 . H p$ & $2 . D$ & $3 . H y$ & $4 . P s$ & $5 . M f$ & $6 . P a$ & $7 . P t$ & $8 . S c$ & $9 . M a$ & $0 . I t$ & \\
\hline \hline$\# 1$ & 55 & 65 & 50 & 52 & 65 & 57 & 63 & 56 & 61 & 61 & 60 & 51 & 59 & norm \\
\hline$\# 2$ & 50 & 73 & 53 & 56 & 73 & 63 & 53 & 61 & 53 & 60 & 69 & 45 & 61 & org \\
\hline$\# 3$ & 56 & 78 & 55 & 60 & 59 & 54 & 67 & 52 & 77 & 56 & 60 & 68 & 63 & paran \\
\hline$\ldots$ & $\ldots$ & $\ldots$ & $\ldots$ & $\ldots$ & $\ldots$ & $\ldots$ & $\ldots$ & $\ldots$ & $\ldots$ & $\ldots$ & $\ldots$ & $\ldots$ & $\ldots$ & $\ldots$ \\
\hline
\end{tabular}

TABLE II

EXEMPLARY FUZZIFICATION OF DESCRIPTIVE ATTRIBUTE VALUES (FOR CASE \#1)

\begin{tabular}{|c||c|c|c|c|}
\hline Attribute $A_{i}$ & $A_{i_{1}}$ & $A_{i_{2}}$ & $A_{i_{3}}$ & $A_{i_{4}}$ \\
\hline \hline$A_{1}$ & 0.077734 & 0.922266 & 0.000000 & 0.000000 \\
\hline$A_{2}$ & 0.298226 & 0.701774 & 0.000000 & 0.000000 \\
\hline$A_{3}$ & 0.000000 & 0.771691 & 0.228309 & 0.000000 \\
\hline$A_{4}$ & 1.000000 & 0.000000 & 0.000000 & 0.000000 \\
\hline$A_{5}$ & 0.453095 & 0.546905 & 0.000000 & 0.000000 \\
\hline$A_{6}$ & 0.858034 & 0.141966 & 0.000000 & 0.000000 \\
\hline$A_{7}$ & 0.238494 & 0.761506 & 0.000000 & 0.000000 \\
\hline$A_{8}$ & 0.119084 & 0.880916 & 0.000000 & 0.000000 \\
\hline$A_{9}$ & 0.725949 & 0.274051 & 0.000000 & 0.000000 \\
\hline$A_{10}$ & 0.579492 & 0.420508 & 0.000000 & 0.000000 \\
\hline$A_{11}$ & 0.873296 & 0.126704 & 0.000000 & 0.000000 \\
\hline$A_{12}$ & 0.781460 & 0.218540 & 0.000000 & 0.000000 \\
\hline$A_{13}$ & 0.000000 & 0.782395 & 0.217605 & 0.000000 \\
\hline
\end{tabular}

There are two tuning parameters $\alpha$ and $\beta$ used in the algorithm. Expanding a tree branch is stopped when either the frequency $f$ of the branch is below $\alpha$ or when more than $\beta$ per cent of cases left in the branch have the same decision class label.

\section{EXPERIMENTS}

Experiments have been performed on a data set described in Section II. Each descriptive attribute has been fuzzified using four partitions (see an example in Table II). An exemplary fuzzy decision tree is shown in Figure 2. A decision attribute $C l$ has been fuzzified using 20 partitions because it has symbolic character (see an example in Table III). Cases are classified into 20 decision classes.

We have calculated fuzzy decision trees for several parameters $\alpha$ and $\beta$. The results (classification ability) of experiments are collected in Table IV. The best classification result has been obtained for $\alpha=0.001$ and $\beta=0.999$. We can compare classification ability of the presented approach with other classic machine learning approaches (see Table V).

We also refer the readers to our earlier papers where results of classification of MMPI profiles using a variety of approaches are presented. In [17], we have described the tests of several algorithms included in the following software tools:

- The Rough Set Exploration System (RSES) - a software tool featuring a library of methods and a graphical user interface supporting a variety of rough set based computations [18].

- NGTS - a system developed to generate decision rules using the algorithm called GTS (General-To-Specific) [19].
TABLE IV

RESULTS OF EXPERIMENTS FOR DIFFERENT PARAMETERS $\alpha$ AND $\beta$

\begin{tabular}{|c||c|c|c|}
\hline$\alpha$ & $\beta$ & $\begin{array}{c}\text { Average } \\
\text { classification error }\end{array}$ & $\begin{array}{c}\text { Standard } \\
\text { deviation }\end{array}$ \\
\hline 0.001 & 0.999 & 0.0823 & 0.0121 \\
\hline 0.001 & 0.989 & 0.0823 & 0.0121 \\
\hline 0.001 & 0.979 & 0.0829 & 0.0122 \\
\hline 0.001 & 0.969 & 0.0838 & 0.0123 \\
\hline 0.001 & 0.959 & 0.0846 & 0.0123 \\
\hline 0.001 & 0.949 & 0.0854 & 0.0124 \\
\hline 0.001 & 0.939 & 0.0865 & 0.0125 \\
\hline 0.001 & 0.929 & 0.0878 & 0.0128 \\
\hline 0.001 & 0.919 & 0.0896 & 0.0130 \\
\hline 0.001 & 0.909 & 0.0915 & 0.0135 \\
\hline 0.001 & 0.899 & 0.0937 & 0.0137 \\
\hline 0.001 & 0.889 & 0.0959 & 0.0138 \\
\hline 0.001 & 0.879 & 0.0978 & 0.0141 \\
\hline 0.001 & 0.869 & 0.1001 & 0.0146 \\
\hline 0.001 & 0.859 & 0.1030 & 0.0149 \\
\hline 0.011 & 0.999 & 0.1646 & 0.1288 \\
\hline 0.011 & 0.989 & 0.1648 & 0.1288 \\
\hline 0.011 & 0.979 & 0.1650 & 0.1288 \\
\hline 0.011 & 0.969 & 0.1653 & 0.1288 \\
\hline 0.011 & 0.959 & 0.1656 & 0.1288 \\
\hline 0.011 & 0.949 & 0.1660 & 0.1288 \\
\hline 0.011 & 0.939 & 0.1667 & 0.1289 \\
\hline 0.011 & 0.929 & 0.1675 & 0.1289 \\
\hline 0.011 & 0.919 & 0.1684 & 0.1289 \\
\hline 0.011 & 0.909 & 0.1693 & 0.1289 \\
\hline 0.011 & 0.899 & 0.1703 & 0.1289 \\
\hline 0.011 & 0.889 & 0.1715 & 0.1289 \\
\hline 0.011 & 0.879 & 0.1727 & 0.1290 \\
\hline 0.011 & 0.869 & 0.1745 & 0.1290 \\
\hline 0.011 & 0.859 & 0.1766 & 0.1291 \\
\hline 0.021 & 0.999 & 0.2100 & 0.1816 \\
\hline 0.021 & 0.989 & 0.2102 & 0.1816 \\
\hline 0.021 & 0.979 & 0.2102 & 0.1816 \\
\hline 0.021 & 0.969 & 0.2103 & 0.1816 \\
\hline 0.021 & 0.959 & 0.2104 & 0.1816 \\
\hline 0.021 & 0.949 & 0.2110 & 0.1817 \\
\hline & & & \\
\hline
\end{tabular}

TABLE V

COMPARISON OF CLASSIFICATION ABILITIES OF DIFFERENT APPROACHES

\begin{tabular}{|c||c|c|}
\hline Method & $\begin{array}{c}\text { Average } \\
\text { classification error }\end{array}$ & $\begin{array}{c}\text { Standard } \\
\text { deviation }\end{array}$ \\
\hline FDT & $\mathbf{0 . 0 8 2 3}$ & $\mathbf{0 . 0 1 2 1}$ \\
\hline C4.5 & 0.0952 & 0.0149 \\
\hline CART & 0.1407 & 0.1287 \\
\hline Bayes & 0.1531 & 0.1288 \\
\hline k-NN & 0.0937 & 0.0129 \\
\hline
\end{tabular}




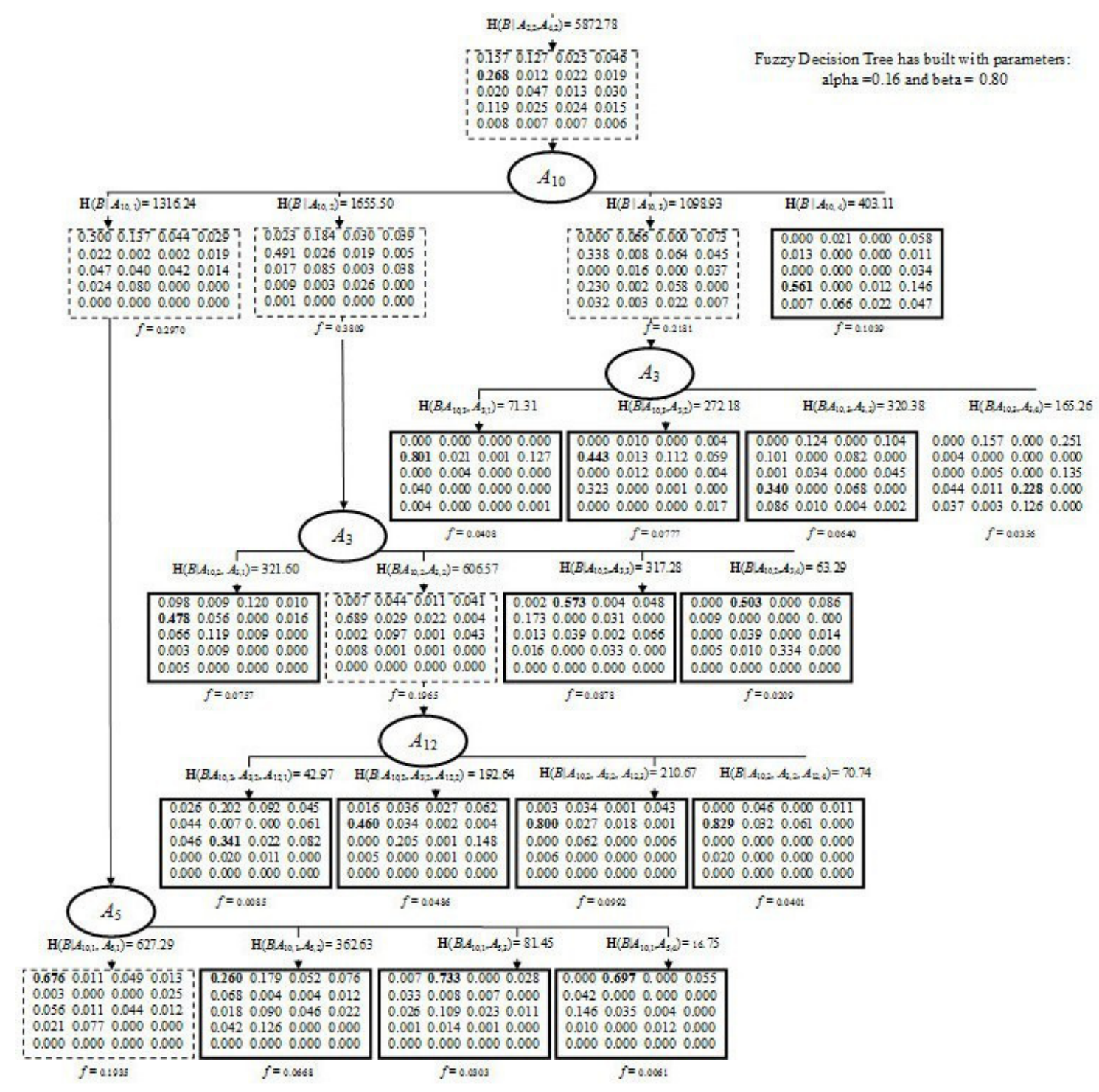

Fig. 2. An exemplary fuzzy decision tree.

- TreeSEEKER - a system containing several algorithms to generate decision trees [20].

- RuleSEEKER - a tool for generation and optimization of rule sets [21].

The main goal of experiments described in [22] was generation of efficient classification (decision) rules via decision trees on the basis of profiles of patients and selected indexes (e.g. Eichmann's indexes, Goldberg's indexes, Leary's indexes), calculated for profiles. Indexes added to profiles (scales) have been calculated using the Copernicus system. Next, for decision tree generation, the well-known C4.5 algorithm [23] (implemented in WEKA) has been used. Experiments with basic profiles (validity and clinical scales) and the extended ones (by adding different specialized indexes defined in the professional domain literature) have also been described in [24]. In [25], we have shown that it is possible to improve classification accuracy of MMPI profiles by reduction or extension of the number of attributes with relation to the original data table. In [26], a problem of hybridization and optimization of the knowledge base for the Copernicus system has been presented. Another tests of classification algorithms, based on decision trees available in the WEKA system [3], have been described in [27]. The review of the variety of approaches (not only machine learning) implemented so far in the Copernicus system is shown in [10].

\section{CONCLUSIONS AND FURTHER WORK}

In the paper, we have presented another machine learning approach, based on fuzzy decision trees, for classification of psychometric data that is planned to be implemented in the Copernicus system - a tool for computer-aided diagnosis of mental disorders based on data coming from psychometric 
TABLE III

EXEMPLARY FUZZIFICATION OF DECISION ATTRIBUTE VALUES (FOR CASE \#1)

\begin{tabular}{|c|c|c|c|c|c|c|c|c|c|c|c|c|c|c|c|c|c|c|c|}
\hline $\mathrm{Cl}_{1}$ & $\mathrm{Cl}_{2}$ & $\mathrm{Cl}_{3}$ & $\mathrm{Cl}_{4}$ & $\mathrm{Cl}_{5}$ & $\mathrm{Cl}_{6}$ & $\mathrm{Cl}_{7}$ & $\mathrm{Cl}_{8}$ & $\mathrm{Cl}_{9}$ & $\mathrm{Cl}_{10}$ & $\mathrm{Cl}_{11}$ & $\mathrm{Cl}_{12}$ & $\mathrm{Cl}_{13}$ & $\mathrm{Cl}_{14}$ & $\mathrm{Cl}_{15}$ & $\mathrm{Cl}_{16}$ & $\mathrm{Cl}_{17}$ & $\mathrm{Cl}_{18}$ & $\mathrm{Cl}_{19}$ & $\mathrm{Cl}_{20}$ \\
\hline 1.00 & 0.00 & 0.00 & 0.00 & 0.00 & 0.00 & 0.00 & 0.00 & 0.00 & 0.00 & 0.00 & 0.00 & 0.00 & 0.00 & $\begin{array}{c}0.00 \\
\end{array}$ & 0.00 & 0.00 & 0.00 & 0.00 & $\overline{0.00}$ \\
\hline
\end{tabular}

tests. The presented approach is based on cumulative information estimations of initial data. Results of experiments against a background of our previous research looks very promising. The main goal of further work is to develop the interpretation of fuzzified attribute values and obtained decision rules from the point of view of diagnosticians. Moreover, there is a need to optimize the transformation method of attribute values from numeric to fuzzy set partition variables. The current version seems to be not optimal.

\section{ACKNOWLEDGMENT}

The research has been partially supported by the grant No. SK-PL-0023-12 under Research and Development Cooperation Slovakia-Poland.

\section{REFERENCES}

[1] K. Cios, W. Pedrycz, R. Swiniarski, and L. Kurgan, Data mining. A knowledge discovery approach. New York: Springer, 2007. [Online]. Available: http://dx.doi.org/10.1007/978-0-387-36795-8

[2] T. M. Mitchell, Machine Learning. New York: McGraw-Hill, 1997.

[3] I. H. Witten and E. Frank, Data Mining: Practical Machine Learning Tools and Techniques. Morgan Kaufmann, 2005.

[4] D. Lachar, The MMPI: Clinical assessment and automated interpretations. Fate Angeles: Western Psychological Services, 1974.

[5] W. Duch, T. Kucharski, J. Gomuła, and R. Adamczak, Machine learning methods in analysis of psychometric data. Application to Multiphasic Personality Inventory MMPI-WISKAD (in polish), Toruń, 1999.

[6] W. E. Hatcher, "Automated classification of MMPI profiles into psychotic, neurotic or personality disorder types," Computer Programs in Biomedicine, vol. 8, no. 1, pp. 77-80, 1978

[7] P. Pancheri and D. De Fidio, "Dal minnesota multiphasic personality inventory al panda: il mmpi-2 automatico," Tech. Rep.

[8] J. Gomuła, K. Pancerz, and J. Szkoła, "Analysis of MMPI profiles of patients with mental disorders - the first unveil af a new computer tool," in Applications of Systems Science, A. Grzech, P. Swiatek, and K. Brzostowski, Eds. Warsaw, Poland: Academic Publishing House EXIT, 2010, pp. 297-306.

[9] _ - "Computer-aided diagnosis of patients with mental disorders using the copernicus system," in Proceedings of the International Conference on Human System Interaction (HSI 2011), Yokohama, Japan, 2011. doi: 10.1109/HSI.2011.5937378. [Online]. Available: http://dx.doi.org/10.1109/HSI.2011.5937378

[10] D. Jachyra, K. Pancerz, and J. Gomuła, "Multiway classification of MMPI profiles," in Proceedings of the Ninth International Conference on Digital Technologies (DT 2013), E. Zaitseva and V. Levashenko, Eds., Zilina, Slovakia, 2013. doi: 10.1109/DT.2013.6566294 pp. 119-127. [Online]. Available: http://dx.doi.org/10.1109/DT.2013.6566294

[11] V. Levashenko, E. Zaitseva, and S. Puuronen, "Fuzzy classifier based on fuzzy decision tree," in Proceedings of the International Conference on Computer as a Tool (EUROCON 2007). IEEE, 2007. doi 10.1109/EURCON.2007.4400614 pp. 823-827. [Online]. Available: http://dx.doi.org/10.1109/EURCON.2007.4400614

[12] M. Choynowski, Multiphasic Personality Inventory (in polish), Psychometry Laboratory, Polish Academy of Sciences, Warsaw, 1964.

[13] Z. Płużek, Value of the WISKAD-MMPI test for nosological differential diagnosis (in polish), The Catholic University of Lublin, 1971.

[14] Z. Pawlak, Rough Sets. Theoretical Aspects of Reasoning about Data. Dordrecht: Kluwer Academic Publishers, 1991. [Online]. Available: http://dx.doi.org/10.1007/978-94-011-3534-4
[15] V. Levashenko and E. Zaitseva, "Usage of new information estimations for induction of fuzzy decision trees," in Proceedings of the Third International Conference on Intelligent Data Engineering and Automated Learning (IDEAL 2002), ser. Lecture Notes in Computer Science, H. Yin, N. Allinson, R. Freeman, J. Keane, and S. Hubbard, Eds. Springer Berlin Heidelberg, 2002, vol. 2412, pp. 493-499. [Online]. Available: http://dx.doi.org/10.1007/3-540-45675-9_74

[16] H.-M. Lee, C.-M. Chen, J.-M. Chen, and Y.-L. Jou, "An efficient fuzzy classifier with feature selection based on fuzzy entropy," IEEE Transactions on Systems, Man, and Cybernetics, Part B: Cybernetics, vol. 31, no. 3, pp. 426-432, 2001. doi: 10.1109/3477.931536. [Online]. Available: http://dx.doi.org/10.1109/3477.931536

[17] J. Gomuła, W. Paja, K. Pancerz, and Szkoła, "A preliminary attempt to rules generation for mental disorders," in Proceedings of the International Conference on Human System Interaction (HSI 2010), Rzeszów, Poland, 2010. doi: 10.1109/HSI.2010.5514483. [Online]. Available: http://dx.doi.org/10.1109/HSI.2010.5514483

[18] J. G. Bazan and M. S. Szczuka, "The Rough Set Exploration System," in Transactions on Rough Sets III, ser. LNAI, J. Peters and A. Skowron, Eds. Berlin Heidelberg: Springer-Verlag, 2005, vol. 3400, pp. 37-56. [Online]. Available: http://dx.doi.org/10.1007/11427834_2

[19] Z. Hippe, "Machine learning: a promising strategy for business information processing?" in Business Information Systems, W. Abramowicz, Ed. Poznan: Academy of Economics Editorial Office, 1997, pp. 603-622.

[20] M. Knap, "Research on new algorithms for decision trees generation (in polish)," Ph.D. dissertation, AGH University of Science and Technology, Krakow, 2009.

[21] W. Paja and Z. Hippe, "Feasibility studies of quality of knowledge mined from multiple secondary sources. I: Implementation of generic operations," in Intelligent Information Processing and Web Mining, ser. Advances in Intelligent and Soft Computing, M. Klopotek, S. Wierzchon, and K. Trojanowski, Eds. Berlin Heidelberg: Springer-Verlag, 2005, vol. 31, pp. 461-465. [Online]. Available: http://dx.doi.org/10.1007/3-540-32392-9 53

[22] J. Gomuła, K. Pancerz, and J. Szkoła, "Copernicus - an expert system supporting differential diagnosis of patients examined using the MMPI test: an index-rule approach," in Proceedings of the International Conference on Health Informatics (HEALTHINF 2011), V. Traver, A. Fred, J. Filipe, and H. Gamboa, Eds., Rome, Italy, 2011. doi: 10.5220/0003172503230328 pp. 323-328. [Online]. Available: http://dx.doi.org/10.5220/0003172503230328

[23] J. Quinlan, C4.5: Programs for Machine Learning. Morgan Kaufmann, 1992.

[24] J. Gomuła, K. Pancerz, and J. Szkoła, "Rule-based classification of MMPI data of patients with mental disorders: Experiments with basic and extended profiles," International Journal of Computational Intelligence Systems, vol. 4, no. 5, 2011.

[25] - ,Classification of MMPI profiles of patients with mental disorders - experiments with attribute reduction and extension," in Rough Set and Knowledge Technology, ser. LNAI, J. Yu et al., Eds. Berlin Heidelberg: Springer-Verlag, 2010, vol. 6401, pp. 411-418. [Online]. Available: http://dx.doi.org/10.1007/978-3-642-16248-0_58

[26] J. Gomuła, W. Paja, K. Pancerz, T. Mroczek, and M. Wrzesień, "Experiments with hybridization and optimization of the rules knowledge base for classification of MMPI profiles," in Advances on Data Mining: Applications and Theoretical Aspects, ser. LNAI, P. Perner, Ed. Berlin Heidelberg: Springer-Verlag, 2011, vol. 6870, pp. 121-133. [Online]. Available: http://dx.doi.org/10.1007/978-3-642-23184-1_10

[27] D. Jachyra, K. Pancerz, and J. Gomuła, "Classification of mmpi profiles using decision trees," in Proceedings of the Workshop on Concurrency, Specification and Programming (CS\&P 2011), M. Szczuka, L. Czaja, A. Skowron, and M. Kacprzak, Eds., Pułtusk, Poland, 2011, pp. 397 407. 